Research article

Open Access

\title{
Identification, Isolation and Characterization of an Unknown Impurity of Varenicline
}

\author{
Balasubramanian SatheeSh * ${ }^{1,2}$, Kondayampettai K. SRee GaneSH ${ }^{1}$, \\ Dhandayutham SARAVANAN $^{2}$
}

${ }^{1}$ Analytical Research and Development, Integrated Product Development, Dr. Reddy's Laboratories Ltd., Bachupally, Hyderabad-500 072, India.

${ }^{2}$ Department of chemistry, National College, Trichy-620 001, India.

* Corresponding author. E-mail: b_satheeesh@yahoo.com (B. Satheesh)

Sci Pharm. 2012; 80: 329-336

doi:10.3797/scipharm.1201-08

Published: $\quad$ March $20^{\text {th }} 2012$

Accepted: $\quad$ March $20^{\text {th }} 2012$

Received: January $15^{\text {th }} 2012$

This article is available from: http://dx.doi.org/10.3797/scipharm.1201-08

(c) Satheesh et al.; licensee Österreichische Apotheker-Verlagsgesellschaft m. b. H., Vienna, Austria.

This is an Open Access article distributed under the terms of the Creative Commons Attribution License (http://creativecommons.org/licenses/by/3.0/), which permits unrestricted use, distribution, and reproduction in any medium, provided the original work is properly cited.

\begin{abstract}
An unknown impurity formed during stability sample analysis by a gradient reversed phase ultra-high pressure liquid chromatography (UHPLC) of varenicline tablets at $0.2 \%$ level. A simple isocratic preparative method was developed to isolate the unknown impurity with 20 min run time. This unknown impurity was identified and characterized by using spectroscopic techniques. Based on the spectral data, the unknown impurity has been characterized as 4,6,7,8,9,10-hexahydro-1H-6,10-methanopyrazino[2,3- $h][3]$ benzazepine-2,3dione. The structure of this impurity was also established unambiguously, prepared by isolation and co-injected into UHPLC to confirm the retention time. To the best of our knowledge, this impurity has not been reported elsewhere.
\end{abstract}

\section{Keywords}

Varenicline • Degradant impurity • Preparative HPLC • Isolation • Characterization

\section{Introduction}

Varenicline is a highly selective partial agonist of the nicotinic acetylcholine receptor $\alpha 4 \beta 2$ subtype [1]. In animal models, the $\alpha 4 \beta 2$ nicotinic receptor has been shown to be responsible for the reinforcing properties of nicotine. Both nicotine and varenicline bind to this receptor subtype. Binding of nicotine to this receptor subtype causes dopamine 
release in the mesolimbic "reward" system (nucleus, accumbens). It is hypothesized that varenicline, a partial agonist, blocks the full-agonist activity of nicotine by competitive binding. As varenicline has this partial agonistic action, it may cause relief of withdrawal and craving symptoms. Withdrawal and craving symptoms are thought to maintain nicotine addiction, and diminishing these symptoms would promote smoking cessation. High performance liquid chromatography (HPLC) is a proven technique that has been used worldwide for many years in controlling the quality and consistency of active pharmaceutical ingredients (APIs) and dosage forms.

Reports on process related impurities [2, 3] and degradation impurities [4] for Varenicline tablets are available in the literature [5]. Additionally, reports on LCMS methods for varenicline are available in the literature [6]. A validated UHPLC method was used [7] for the identification.

It is a mandatory requirement from regulatory authorities to identify and characterize any unknown impurity formed during stability condition which is more than $0.2 \%$ in the drug product [8-12]. A comprehensive study has been undertaken to isolate and characterize the unknown impurity by spectroscopic techniques [13-15]. This research paper describes the preparative separation, isolation, identification and characterization of an unknown impurity of Varenicline tablets.

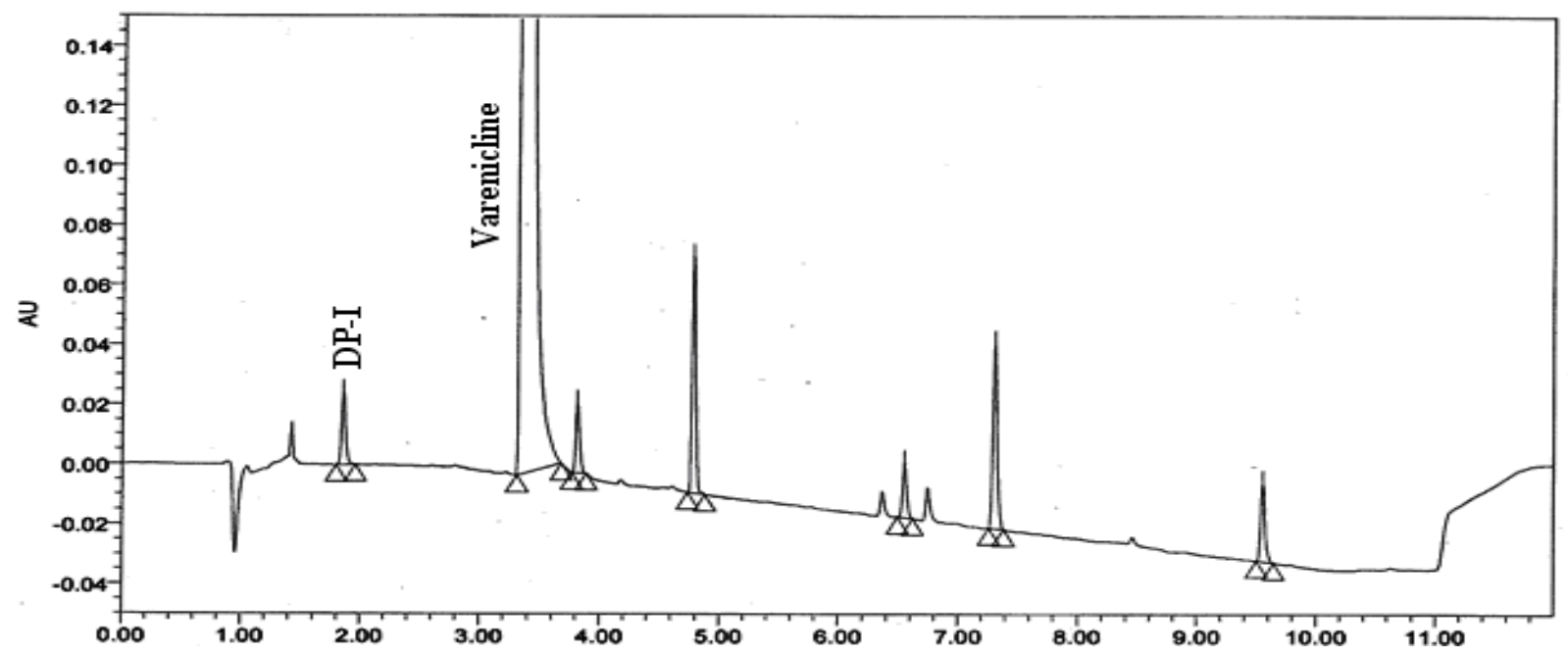

Fig. 1. UHPLC stability chromatogram of Varenicline tablet sample.

\section{Experimental}

\section{Chemicals and reagents}

The investigated samples of varenicline drug product were obtained from in-house of Dr. Reddy's laboratories. Methanol, Acetonitrile, acetic acid was of HPLC grade and Ammonium acetate was of Analytical grade procured from Merck (Germany). Water was purified by a Milli-Q-water purification system (Millipore, Bedford, MA, USA) and used for preparation of all the solutions. Pharmaceutical excipients (Microcrystalline cellulose, anhydrous calcium hydrogen phosphate, croscarmellose sodium, anhydrous colloidal silica, magnesium stearate, Titanium dioxide and Iron oxide) were procured from vendor. 
Dimethyl sulphoxide- $d_{6}$ (for NMR) was purchased from Aldrich Chemical Co., USA). All solutions were filtered through $0.45 \mu \mathrm{m}$ membrane filters (Whatman) and degassed by sonication prior to use.

\section{Ultra performance liquid chromatography (analytical)}

The UHPLC system was utilized using a Waters Acquity system equipped with binary solvent delivery pump, an auto sampler and PDA UV detector. The chromatographic separation was performed using a Waters Acquity HSS T3 $(150 \times 2.1 \mathrm{~mm}, 1.8 \mu \mathrm{m})$, the mobile phase $A$ consists of a mixture of Ammonium acetate buffer ( $\mathrm{pH} 6.5 ; 0.01 \mathrm{M}$ ) and $B$

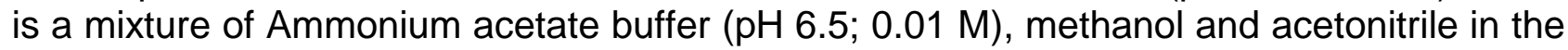
ratio of 10:25:65 (v/v/v). The gradient programme "T (min)/ \% B": 0/2, 1/2, 9/90, 10/90, $10.1 / 2$ and $12 / 2$, with flow rate of $0.35 \mathrm{~mL} / \mathrm{min}$ was employed. The injection volume was maintained at $5 \mu \mathrm{L}$ and detector set at $235 \mathrm{~nm}$. The column temperature was kept at $40^{\circ} \mathrm{C}$.

\section{Forced degradation of varenicline tablets}

Forced degradation studies were performed on the varenicline tablets with the intention of determining the conditions responsible for the formation of the degradation products. Accordingly, degradation studies were conducted by stressing with acid, base, aqueous, peroxide and heat.

\section{Acid stressed degradation}

Two hundred milligrams equivalent of varenicline tablets were dissolved in $20 \mathrm{~mL}$ of methanol and water in the ratio of $1: 1,5 \mathrm{~mL}$ of $0.1 \mathrm{~N} \mathrm{HCl}$ solution was added and refluxed for about $4 \mathrm{~h}$ and neutralized.

\section{Base stressed degradation}

Two hundred milligrams equivalent of varenicline tablets were dissolved in $20 \mathrm{~mL}$ of methanol and water in the ratio of $1: 1,5 \mathrm{~mL}$ of $0.1 \mathrm{~N} \mathrm{NaOH}$ solution was added and refluxed for about $4 \mathrm{~h}$ and neutralized.

\section{Aqueous stressed degradation}

Two hundred milligrams equivalent of varenicline tablets were dissolved in $20 \mathrm{~mL}$ of methanol and water in the ratio of 1:1, the solution was refluxed for about $4 \mathrm{~h}$.

\section{Peroxide stressed degradation}

Two hundred milligrams equivalent of varenicline tablets were dissolved in $20 \mathrm{~mL}$ of methanol and water in the ratio of $1: 1,5 \mathrm{~mL}$ of $6 \%$ hydrogen peroxide solution was added and maintained at $60^{\circ} \mathrm{C}$ for $4 \mathrm{~h}$.

\section{Thermal stressed degradation}

Two hundred milligrams equivalent of varenicline tablets were taken in a Petri dish. Water was sprinkled on the tablets and subjected to $60^{\circ} \mathrm{C}$ for $3 \mathrm{~h}$.

Results of forced degradation study

The degradation samples were analyzed by UHPLC method [7]. Under peroxide stressed 
conditions, DP-I was formed up to $24 \%$. Attempts were then made to isolate the unknown impurity from peroxide stressed sample.

\section{High performance liquid chromatography (preparative)}

Impurity was isolated from the sample using Shimadzu preparative HPLC Binary system which was equipped with Dual wavelength detector. The data was collected and processed using Millennium software. Approximately $50 \mathrm{mg} / \mathrm{mL}$ of sample was prepared to load on to the column. An Inertsil ODS $(250 \times 20 \mathrm{~mm}, 10 \mu \mathrm{m})$ column was employed for the separation of DP-I. The mobile phase is consisting of a mixture of $0.02 \mathrm{M}$ ammonium acetate buffer, with the $\mathrm{pH}$ adjusted to 6.5 with ammonia and methanol in the ratio of (70:30). The flow rate was kept at $15 \mathrm{~mL} / \mathrm{min}$. Detection was carried out at $235 \mathrm{~nm}$.

\section{Sample preparation}

The varenicline sample was prepared at a concentration of $1 \mathrm{mg} / \mathrm{mL}$ in methanol for the analytical UHPLC and $50 \mathrm{mg} / \mathrm{mL}$ for the preparative HPLC analysis.

\section{UHPLC-TOF MS}

The UHPLC-ToF MS system consisted of an ACQUITYTM Ultra Performance Liquid Chromatography system and a Micro mass LCT Premier XE Mass Spectrometer (High sensitivity orthogonal time-of-flight instrument, Waters, Modiford, USA) equipped with a lock mass sprayer, operating in either the positive or negative ion mode. All analyses were acquired using the lock spray to ensure accuracy and reproducibility; leucine-enkephalin was used as the lock mass. Sample of concentration $0.02 \mathrm{mg} / \mathrm{mL}$ in methanol was infused in ToF MS at a flow rate of $10 \mu \mathrm{L} / \mathrm{min}$. High resolution (W mode, FWHM 10500) positive polarity scan responses were collected from $\mathrm{m} / \mathrm{z} 100$ to 1000 at a rate of $1.0 \mathrm{~s} / \mathrm{scan}$.

\section{NMR spectroscopy}

The NMR experiments were performed on Varian spectrometer operating at $400 \mathrm{MHz}$, Mercury plus, in DMSO $-d_{6} \&\left(\mathrm{DMSO}+\mathrm{D}_{2} \mathrm{O}\right.$ for $\left.\mathrm{DP}-\mathrm{I}\right)$ at $25^{\circ} \mathrm{C}$. The proton and carbon chemical shifts were reported on $\delta$ scale in ppm, relative to TMS $(\delta=0.00 p p m)$ and DMSO $(\delta=39.50 \mathrm{ppm})$ as internal standard, respectively.

\section{FT-IR spectroscopy}

IR spectra were recorded in solid state as $\mathrm{KBr}$ dispersion medium using Perkin-Elmer FT-IR spectrophotometer.

\section{Results and Discussion}

\section{Detection of DP-I}

A typical analytical UHPLC chromatogram of a stability sample of Varenicline drug product recorded using the UHPLC method [7] as described are shown in Fig. 1. The target impurity under study is marked as DP-I retention time (RT): 1.857 \& Varenicline (retention time (RT): 3.354. The structure of the DP-I and varenicline are shown in Fig. 2. The representative UHPLC chromatograms of the forced degradation study are shown in Fig. 3. The DP-I is polar with respect to varenicline. 
<smiles>c1cnc2cc3c(cc2n1)C1CNCC3C1</smiles><smiles>O=C(O)C(O)C(O)C(=O)O</smiles>

Varenicline tartrate<smiles>O=c1[nH]c2cc3c(cc2[nH]c1=O)[C@H]1C[C@@H]3CN1</smiles>

Fig. 2. Chemical structures of Varenicline Tartrate and degradant product (DP-I).

\section{Isolation of impurity by preparative HPLC}

Several trials were performed to achieve the required resolution. Finally an isocratic solvent system was developed with good resolution and short runtime. Desaltification procedure was adopted to isolate the impurity as pure fractions. The impurity fractions were collected from several injections and then pooled. These fractions were concentrated separately by using Rotavapor (Heidolph Laboratory 4002 control) under high vacuum. The aqueous solutions were subjected to lyophilization to solidify the impurity.

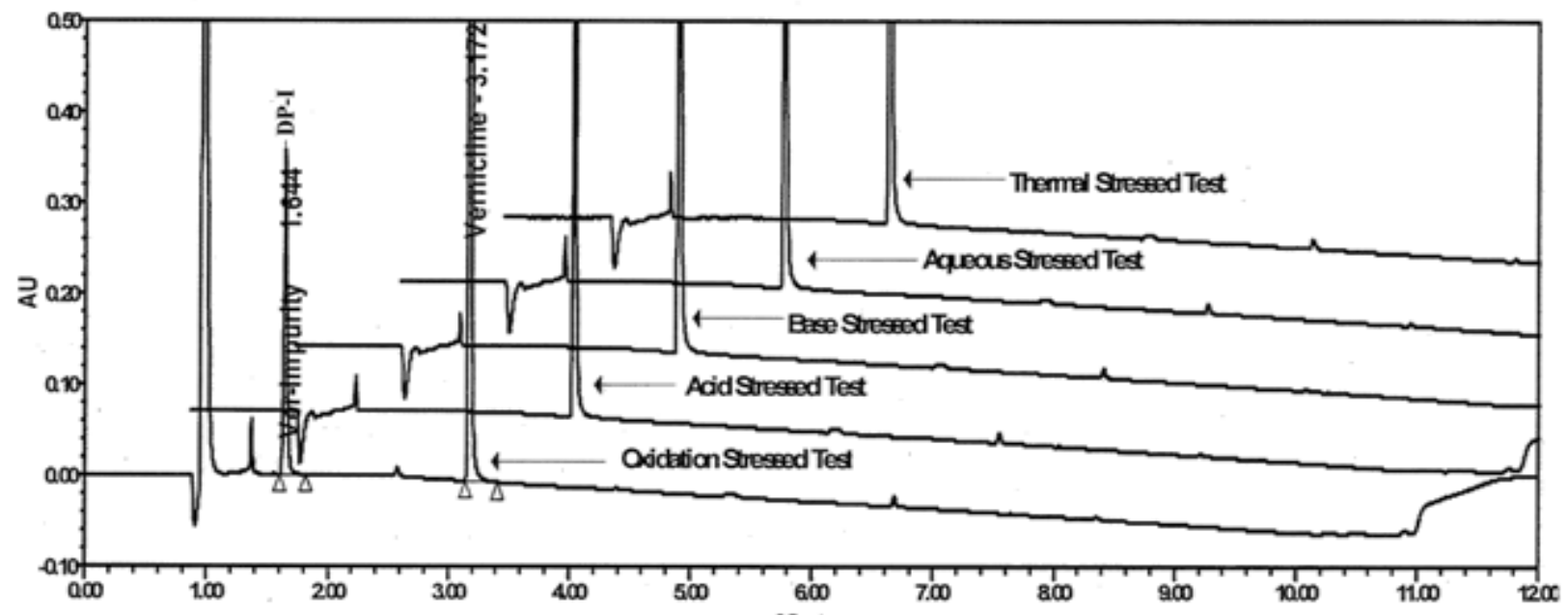

Fig. 3. Comparison of chromatograms obtained from the forced degradation studies.

\section{Characterization of varenicline DP-I}

The ${ }^{1} \mathrm{H}$ NMR and ${ }^{13} \mathrm{C}$ NMR spectra of DP-I are shown in Fig. $4(\mathrm{~A})$ \& (B), respectively. The NMR and High resolution mass spectroscopic (HR-MS) data of the isolated impurity was compared with those of Varnecline tartrate data $\left(\mathrm{C}_{13} \mathrm{H}_{13} \mathrm{~N}_{3}\right)$. The proton NMR of isolated impurity was similar to that of parent compound. The mass (ToF-MS), FT-IR and ${ }^{13} \mathrm{C}$ NMR spectrum reveals important structural insight of the DP-I. The positive HR-MS data Fig. 5 of impurity DP-I has exhibited protonated molecular ion $[\mathrm{M}+\mathrm{H}]^{+}$at 244 , which corresponds to the molecular formula $\mathrm{C}_{13} \mathrm{H}_{14} \mathrm{~N}_{3} \mathrm{O}_{2}$. The molecular formula shows that the impurity has 
two oxygen atoms more than the parent compound. The IR spectrum shows the stretching vibration at $1696 \mathrm{~cm}^{-1}$ reveals the presence of amide carbonyl $(-\mathrm{CONH})$ and the ${ }^{13} \mathrm{C} \mathrm{NMR}$ also confirms the amide carbonyl at $173.8 \mathrm{ppm}$. The above spectral data confirms the oxidation of pyrazine ring.

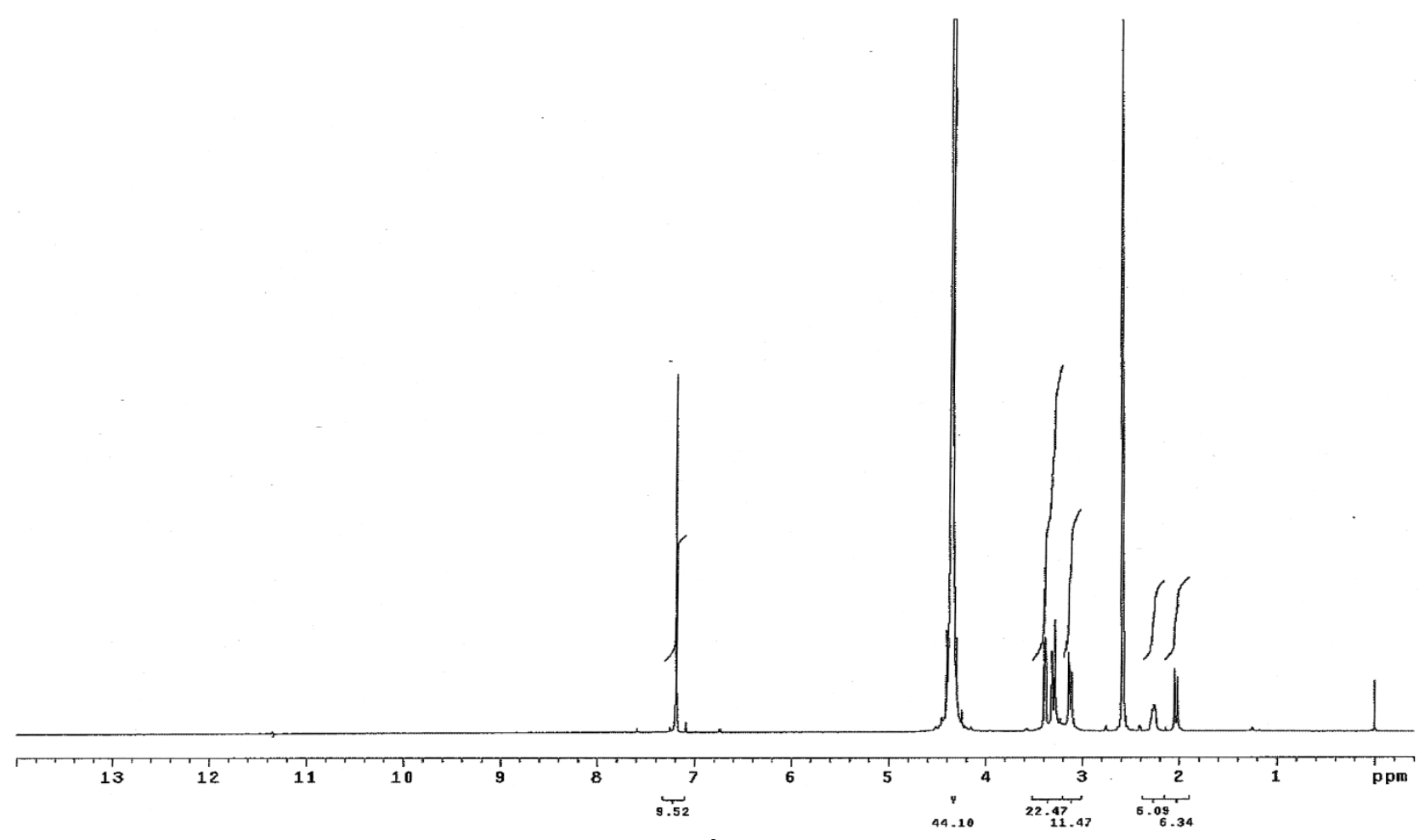

A

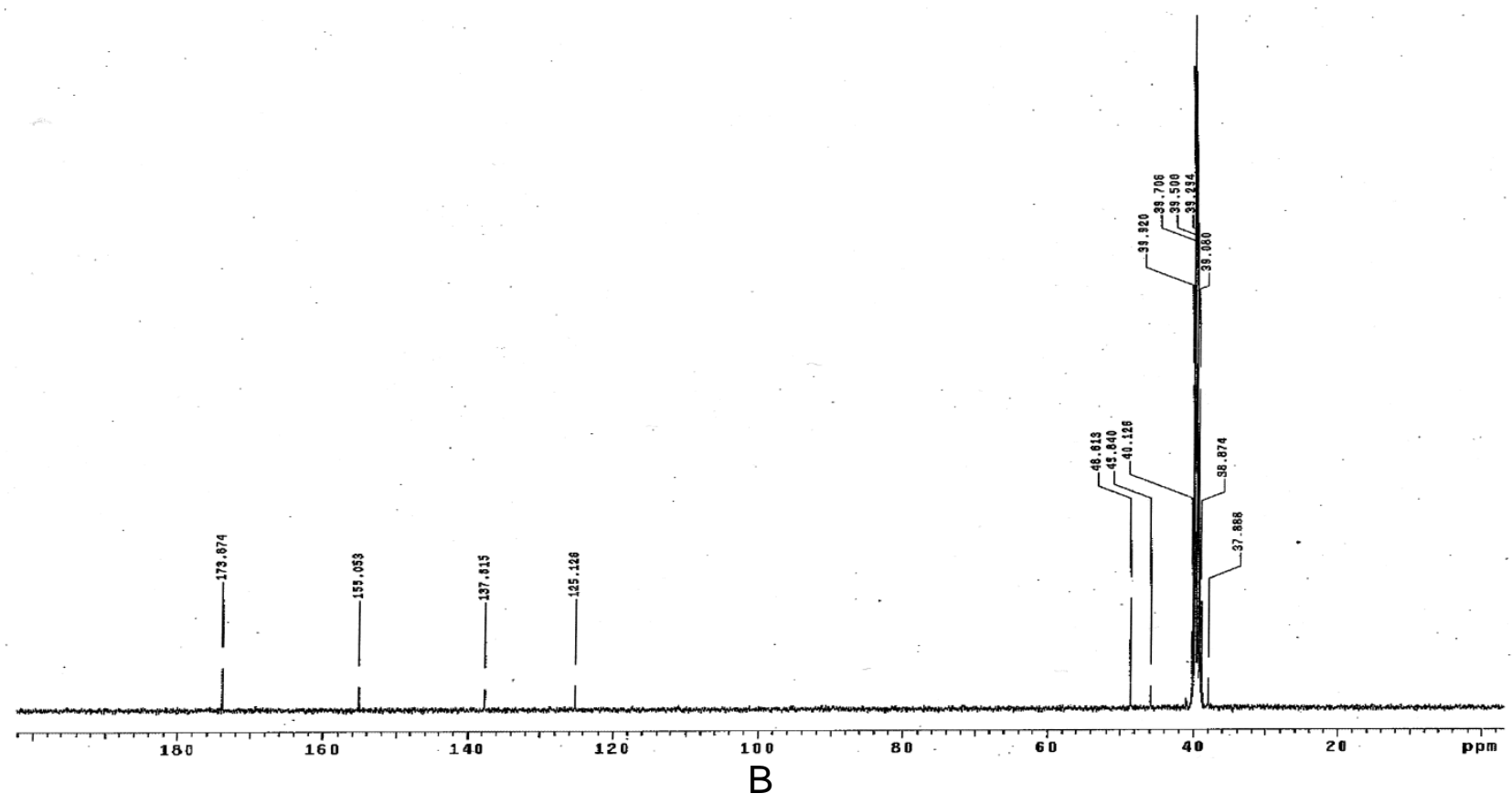

Fig. 4. (A) ${ }^{1} \mathrm{H}$ NMR spectrum of DP-I. (B) Proton decoupled ${ }^{13} \mathrm{C}$ NMR spectrum of DP-I. 
The impurity obtained as pale white crystals. mp 71-73. RP-UHPLC, $\mathrm{tR}=1.8 \mathrm{~min}$ (98.5\% purity). MS (ESI, $70 \mathrm{eV})$ : [M + $\left.\mathrm{H}^{+}\right] \mathrm{m} / \mathrm{z}$ 244. FT-IR (KBr), v, $\mathrm{cm}^{-1}: 3371,3319,3279,3173$, 3005, 2808, 1696, 1678, 1588, 1406, 1388, 1338, 1305, 1264, 1135, 1067, 873, 790, 680, 569, 485. ${ }^{1} \mathrm{H}$ NMR (400 MHz, DMSO- $d_{6}+\mathrm{D}_{2} \mathrm{O}$, TMS): $\delta 7.2(\mathrm{~s}, 2 \mathrm{H}, \mathrm{H}-7,8), 3.1-3.4(\mathrm{~m}, 6 \mathrm{H}$, $\mathrm{H}-11,13,14$ \& 16),2.3 (m, 1H, H-12), $2.0(\mathrm{~d}, 1 \mathrm{H}, 11.2 \mathrm{~Hz}, \mathrm{H}-12) .{ }^{13} \mathrm{C} N M R(100 \mathrm{MHz}$, DMSO- $d_{6}$, TMS): $\delta 173.8$ (C-2,3), 155.1 (C-5,6), 137.6 (C-9,10), 125.1 (C-7,8), 38.8 (C11), 37.9 (C-12), 38.8 (C-13), 45.8 (C-14), 48.6 (C-16). UHPLC ToF MS+: m/z [M + $\mathrm{H}^{+}$].Calcd for $\mathrm{C}_{13} \mathrm{H}_{13} \mathrm{~N}_{3} \mathrm{O}_{2}$ : 244.1086; found: 244.1082.

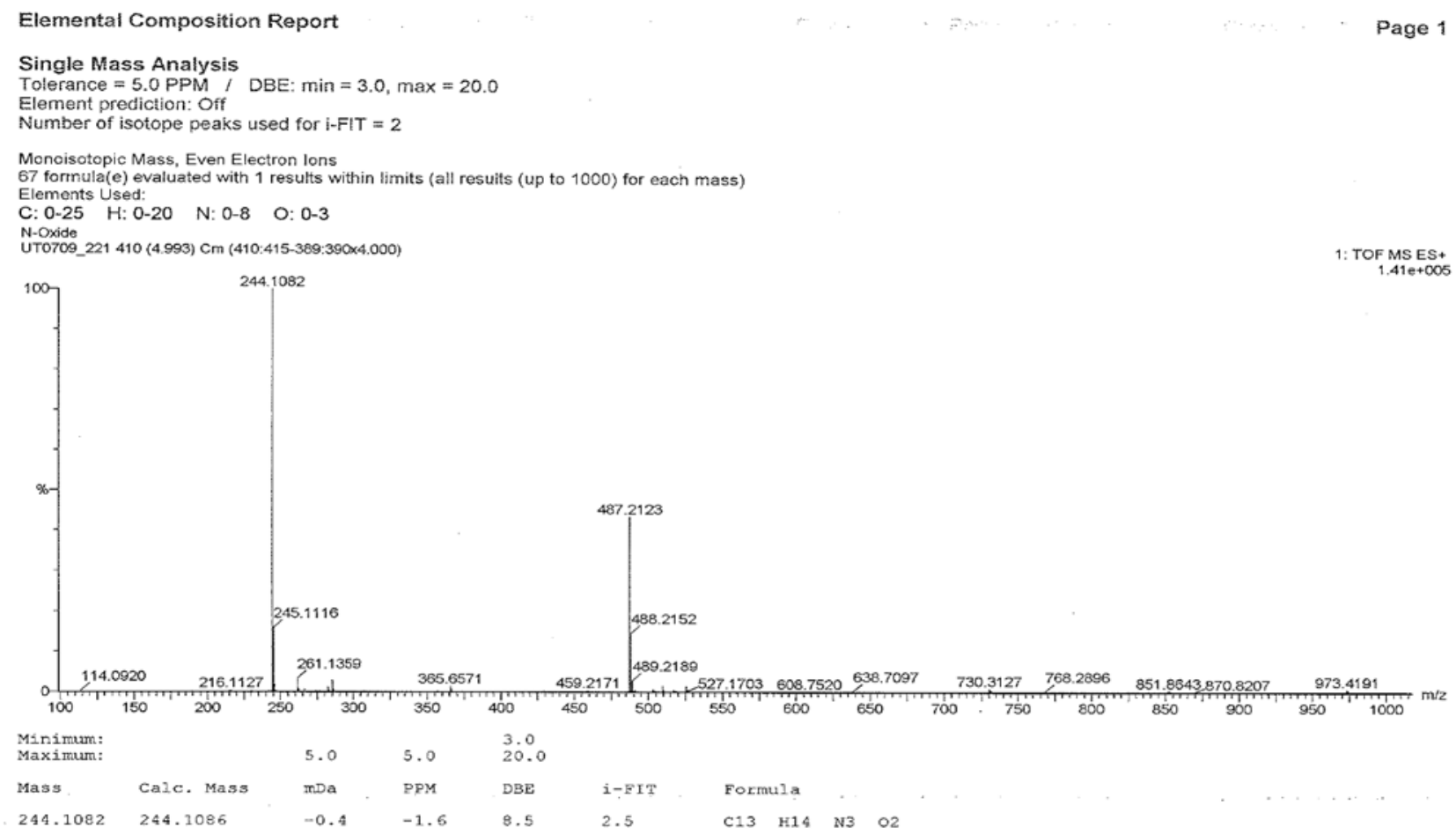

Fig. 5. UHPLC-ToF MS ${ }^{+}$of DP-I.

Based on the above spectral data, the molecular formula of DP-I is $\mathrm{C}_{13} \mathrm{H}_{13} \mathrm{~N}_{3} \mathrm{O}_{2}$ and the corresponding structure was characterized as 4,6,7,8,9,10-hexahydro- $1 \mathrm{H}-6,10$-methanopyrazino[2,3- $h][3]$ benzazepine-2,3-dione.

\section{Acknowledgement}

The author would like to thank the management of Dr. Reddy's laboratories for providing the facility to perform this research.

\section{Authors' Statement \\ Competing Interests}

The authors declare no conflict of interest. 


\section{References}

[1] www.emea.europa.eu/humandocs/PDFs/EPAR/champix/H-699-en6.pdf

[2] Busch FR, Concannon PE, Handfield RE, McKinley JD, McMahon ME, Singer RA, Watson TJ, Withbroe GJ, Stivanello M, Leoni L, Bezze C.

Synthesis of (1-(Aminomethyl)-2,3-dihydro-1H-inden-3-yl)methanol: Structural Confirmation of the Main Band Impurity Found in Varenicline ${ }^{\circledR}$ Starting Material.

Synth Commun. 2008; 38: 441-447.

http://dx.doi.org/10.1080/00397910701771231

[3] Varenicline standards and impurity controls. www.freepatentsonline.com/US2007/0224690.html

[4] N-formyl and N-methyl degradation products. www.freepatentsonline.com/y2004/0235850.html

[5] Methods of reducing degradant formation in pharmaceutical compositions of Varenicline. www.freepatentsonline.com/y2008/0026059.html

[6] Varenicline standards and impurity controls. www.freepatentsonline.com/EP2004186.html

[7] Satheesh B, Kumarpulluru S, Raghavan V, Saravanan D.

UHPLC Separation and Quantification of Related Substances of Varenicline Tartrate Tablet. Acta Chromatogr. 2010; 22: 207-218. http://dx.doi.org/10.1556/AChrom.22.2010.2.4

[8] $\mathrm{ICH}$ harmonized tripartite guideline. Q3A (R2). Current step 4 version dated 25 October 2006.

[9] $\mathrm{ICH}$ harmonized tripartite guideline. Impurities in New Drug products Q3B (R2). Current step 4 version dated 2 June 2006.

[10] $\mathrm{ICH}$ harmonized tripartite guideline. Stability testing of new drug substances and Products Q1A (R2). Current step 4 version dated 6 February 2003.

[11] US Food and Drug Administration. Drug Stability Guidelines, February 1987.

[12] United States Pharmacopeia. 25, US Pharmacopeial Convention, Rockville, MD 2000, 7, General Notices.

[13] Ahuja S, Alsante KM. Handbook of isolation and characterization of impurities in pharmaceuticals. Academic Press, 2003.

[14] Smith RJ, Webb ML. Analysis of Drug Impurities. Blackwell Publsihers, 2007.

[15] Ahuja S. Impurities Evaluation of Pharmaceuticals. Marcel Dekker, NY, 1998. 